\title{
Using Design Thinking to Improve Cook Stoves Development in Mexico
}

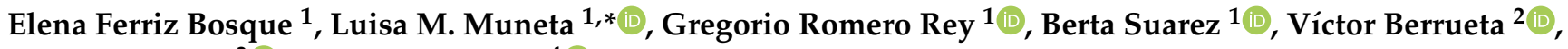 \\ Alberto Beltrán ${ }^{3}\left(\mathbb{D}\right.$ and Omar Masera ${ }^{4}(\mathbb{D}$
}

1 Mechanical Engineering Department, Escuela Técnica Superior de Ingenieros Industriales, Universidad Politécnica de Madrid, 28006 Madrid, Spain; elefb95@gmail.com (E.F.B.); gregorio.romero@upm.es (G.R.R.); b.suarez@upm.es (B.S.)

2 Grupo Interdisciplinario de Tecnología Rural Apropiada (GIRA), Morelia 61613, Mexico; vberrueta@gira.org.mx

3 Instituto de Investigaciones en Materiales, Unidad Morelia, Universidad Nacional Autónoma de México, Morelia 58190, Mexico; albem@materiales.unam.mx

4 Grupo de Innovación Ecotecnológica y Bioenergía (GIEB), Instituto de Investigaciones en Ecosistemas y Sustentabilidad (IIES), Universidad Nacional Autónoma de México (UNAM), Morelia 58190, Mexico; omasera@gmail.com

* Correspondence: luisa.mtzmuneta@upm.es

Citation: Ferriz Bosque, E.; Muneta, L.M.; Romero Rey, G.; Suarez, B.; Berrueta, V.; Beltrán, A.; Masera, O. Using Design Thinking to Improve Cook Stoves Development in Mexico. Sustainability 2021, 13, 3843. https:// doi.org/10.3390/su13073843

Academic Editor: Wen-Hsien Tsai

Received: 27 February 2021

Accepted: 25 March 2021

Published: 31 March 2021

Corrected: 19 May 2022

Publisher's Note: MDPI stays neutral with regard to jurisdictional claims in published maps and institutional affiliations.

Copyright: () 2021 by the authors. Licensee MDPI, Basel, Switzerland. This article is an open access article distributed under the terms and conditions of the Creative Commons Attribution (CC BY) license (https:// creativecommons.org/licenses/by/ $4.0 /)$.

\begin{abstract}
A traditional use of bioenergy is the main source of residential energy in developing countries, essentially using firewood to cook, boil water or heating affecting people in developing countries. Improved cook stoves are more efficient and less polluting, and there is a need to evaluate different design options to facilitate their adoption. There are different types of very economical improved cookstoves with high combustion efficiency. In Mexico, multiple projects about cook stoves have been carried out, the root of this study being one of them: the Patsari cook stoves. The goal of this project was to modify previous stove designs to align with local people's habits and traditions. This study shows the importance of including the participation of users in the design of the portable model of Patsari cook stoves, applying the Design Thinking methodology. Many designs or design changes have been carried out on cook stoves by different researchers, but users often do not adapt to them. This article, through a field study, shows the importance of integrating theoretical analyses along with user experiences to facilitate the adoption of improved cook stoves and ensure their success.
\end{abstract}

Keywords: improved cook stove; Patsari; design thinking; simulations

\section{Introduction}

Bioenergy is referred to as a type of renewable energy, which is obtained from biomass. The current scope and expected evolution of traditional bioenergy use are closely linked to several key challenges to sustainable development, from both local and global environmental concerns to health and gender issues to ensure universal access to clean energy.

Approximately, 2800 million people in the world burn solid biofuels to satisfy basic energy needs, representing more than half of the population of developing countries [1]. Undeveloped and developing countries use bioenergy as their main residential energy source. They use in a traditional stove, a three-stone structure which support the pot [2] in most cases. This burning can result in an incomplete combustion process that emits pollutants that damage health directly, such as particulate matter and carbon monoxide, which contributes to high rates of morbidity and mortality [3]. According to the World Health Organization, four million people in the world die prematurely per year due to in-door pollution and the most vulnerable groups are women and children [4]. In addition, it does not only directly affect health [5]; the hours spent on the collection of firewood and cooking has a direct impact on social equity and community development $[6,7]$. 
Incomplete combustion also produces climate impact emissions such as greenhouse gas like carbon monoxide and methane, and short-life climate forces like carbon monoxide, volatile organic compounds and particulate matter [8]. In terms of climate, not only the emissions are important; traditional bioenergy stands for the $55 \%$ of global wood production, and between $29-34 \%$ of firewood production which is used to satisfy basic needs is unsustainable for reasons of forest regeneration [3].

Most countries of Latin America depend on this kind of bioenergy and Mexico is one of the main ones, where 28 million people depend on firewood to live, up to $90 \%$ of the population in rural areas (Figure 1). In addition, $20 \%$ of firewood production in Mexico is unsustainable [3].

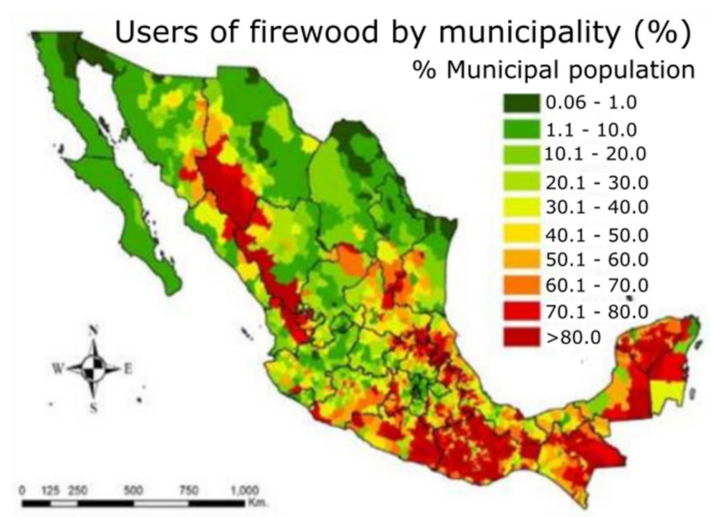

Figure 1. Firewood users in Mexico households. Source: Mexico Government [9].

Despite negative aspects of inadequate use of firewood, according to Food and Agriculture Organization of the United Nations (FAO) [10], the energy that is produced is considered a renewable energy source without any effects on climate. Also, it is viable from a social point of view when firewood comes from sustainable sources and management, and the combustion is efficiently produced. Solid biomass used for cooking and heating is estimated to contribute $25 \%$ of black carbon emissions globally [11]. According to this, improved cook stoves were developed. Results demonstrate the significant potential for firewood savings as a result of installation of the Patsari improved cook stove [12].

\section{Improved Cook Stoves}

An improved cook stoves is an evolution of the traditional cook stoves or three-stone fires. Improved cook stoves are economical devices with high combustion efficiency. They are being developed using new materials that reduce pollution and fuel consumption by $60-90 \%$ [13].

This paper shows the unification on the same working model of the different perspectives of design (experimental, theorical and user's needs). That means a better understanding of the product and its performances to be satisfied by the designers, ensuring higher adoption and success rates.

Globally, several types of enhanced cook stoves have been developed and implemented. They can be classified into four groups [14]:

1. Direct combustion cook stoves: characterized by using efficient combustion chambers, insulating materials, high heat transfer, adequate geometric design and airflow. Models such as Rocket and portable models such as Darfur and StoveTec have been implemented in Africa. In Latin America, models such as Patsari and La Justa have been developed, as well as prefabricated ones such as Ecofogón and ONIL. The price is usually between $\$ 10$ and $\$ 150$. They report energy savings ranging from $30 \%$ to $60 \%$ [6] and an emissions reduction between $80-90 \%$.

2. Gasifiers: designed to work with multiple types of fuel, from pellets or pineapples to cornshell, and may or may not have a fan. They are frequently used in China and 
India and provide between 1 and $3 \mathrm{~kW}$ of electricity with efficiency of between $35 \%$ and $40 \%$.

3. Biogas stoves and other processed fuels: mainly use animal manure or agricultural waste to produce clean energy. They also generate fertilizers and reduce the risk of pathogens. Other cook stoves use processed fuels such as ethanol. They are mostly used in China, India and Nepal.

4. Hybrid stoves: a recent innovation. An example is the generation of electricity through the thermoelectric effect.

This study developed a new model of the portable-metallic Patsari cook stove, which was optimally adapted to the user needs and achieved a higher efficiency and less polluting emissions. The goal was to modify previous designs to align with the habits and traditions, performing the theorical fluid simulations of the stove which allow the best performances and developing the prototypes whose results were the better ones.

Mexico, due to its dependent situation on firewood in rural villages, is one of the main countries where improved cook stoves have been developed by non-governmental organizations (NGO) programs and projects. Nowadays, one of the biggest cook stove programs, and the root of this study, is the Patsari development $[15,16]$. A cook stove which is built in-situ with brick or mud and reduces firewood consumption and in-door pollution thanks to a chimney. Subsequently, a portable-metallic model was developed but it did not succeed (Figure 2).

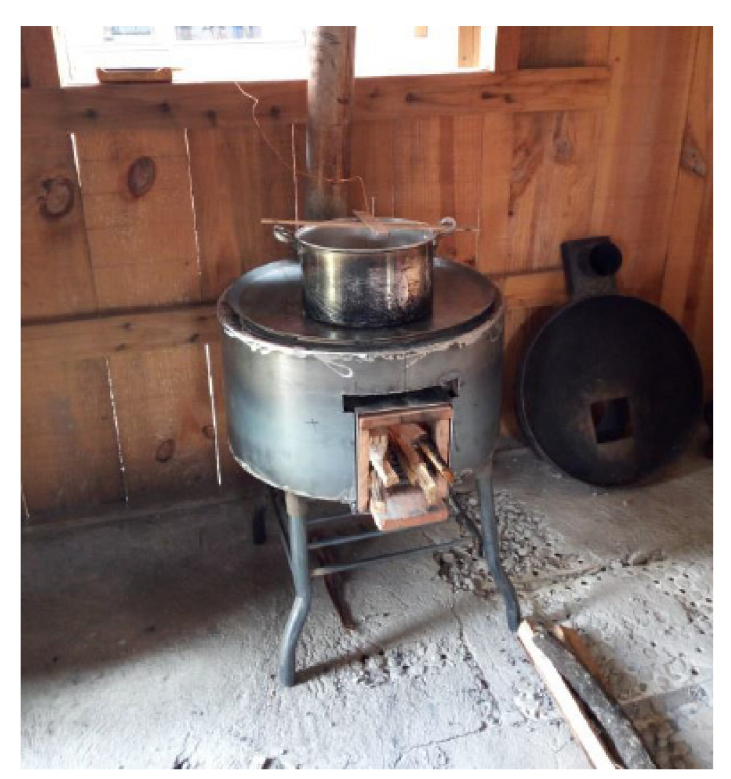

Figure 2. Portable-metallic Patsari.

Many dissemination and implementation strategies have been and are being developed in both Mexico and other countries. Different models, which explain adoption rates and new cooking technologies affects in developing countries, have been built [17]. Originally, the traditional "energy ladder" model was defined [18]. According with it, traditional devices are totally replaced by modern alternatives when family income raised. However, the transition is not unidirectional and people evolve to a "multiple fuel" model where they use more than one different fuel device as they go up in the energy ladder but they do not abandon the traditional ones.

The traditional three-stone fire stoves are not only used for cooking but also give light to homes, warm the space and repel insects. The transition to a different cooking device needs an adaptation process by the users. In addition, the new device has to satisfy every need the user has. Furthermore, every community, village or city in the same country has different traditions and habits. For example, in Mexico people used to cook on a round grill called comal where they cook a typical dish named 'tortillas'. To cook them, the heat 
needs to be distributed in rings, with lower temperature away from the center to the border of the grill. The aim of this work is to include the needs of the user, insights and cultural issues (traditions and habits) in a new model of Patsari cook stove

In fact, one of the reasons for the failure of development cooperation projects is that they have not studied deeply the user's perspective and local traditions. In our study, a Patsari prototype had been installed but local people did not use it because they could not cook their 'tortillas', their traditional and everyday meal.

\section{Materials and Methods}

The technical tests were performed at the Grupo Interdisciplinario de Tecnología Rural Apropiada (GIRA) installations. The simulations were developed at the Universidad Autónoma de México (UNAM) campus. The user evaluations were implemented thanks to interviews and direct observations of a family living in the Sta. Ana de Chapitiro community, which is near to Pátzcuaro, where the prototype objects of this study were installed [19].

Techniques that involve users and based on Design Thinking methodology $[20,21]$ were used. This methodology is a user-centered method that uses a set of tools to achieve empathy with the user and understand the problem from the point of view of the user. It is a general design method suitable for both product design and service development or organization management. According to Design Thinking schools, five [20] or four [21] stages are established, which include knowledge related to the problem to be addressed, its definition, the ideation of possible solutions, their prototypes and iteration cycles. In our case we worked to improve and adapt to the use, needs and culture of the user over a Patsari cook stove prototypes already installed (3 units). Traditional design is focused on the use of technology to solve problems and Design Thinking drives determining what does not work in the design as soon as possible, analyzing early and frequent failures [22]. Figure 3 shows a comparison between traditional design and design thinking. Traditional design is focused only on the use of technology to solve problems but Design Thinking focuses beyond on people, and emphasizes designing prototypes and evaluating them with users to begin an improvement process, as well as obtaining products with successful stories and with higher rates of satisfaction between users.
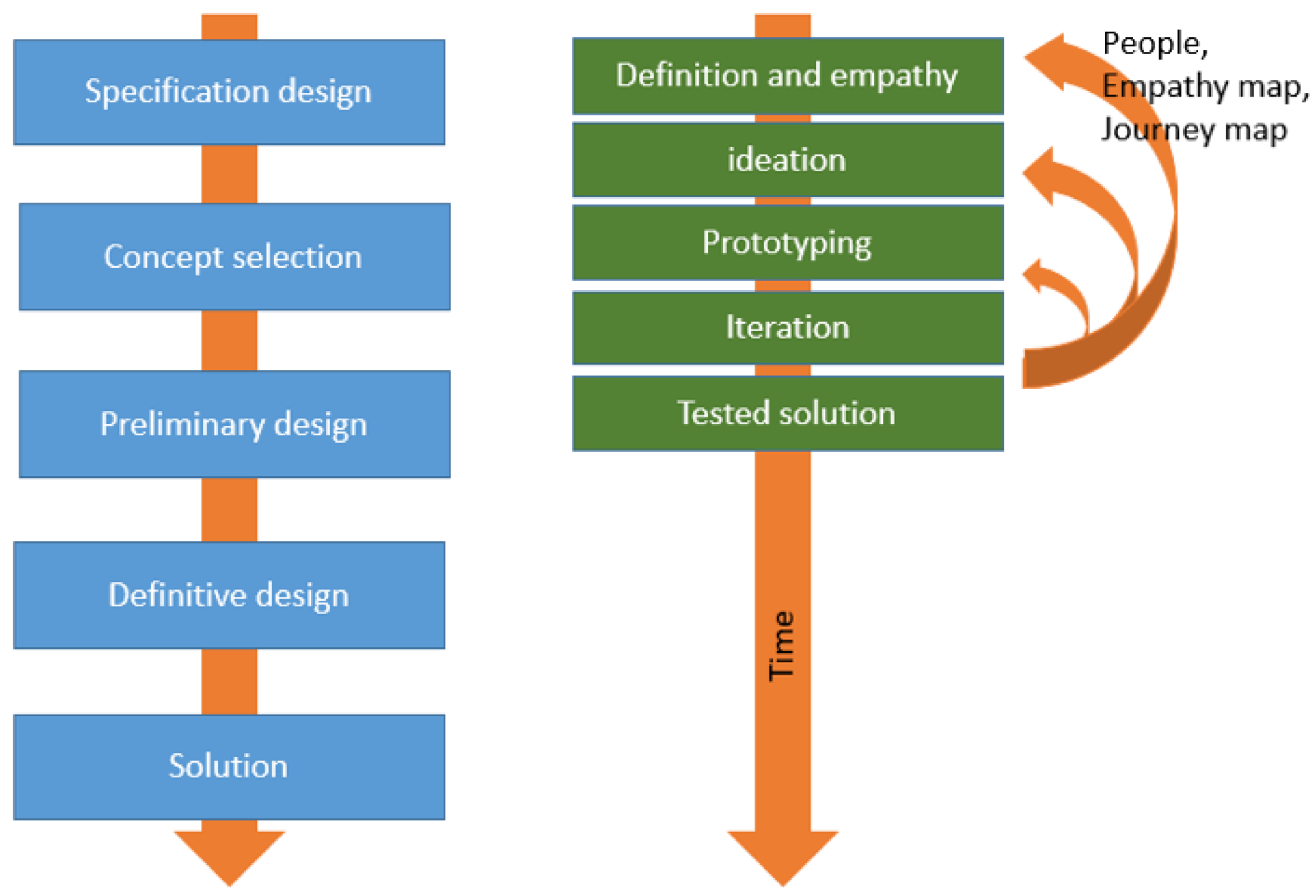

Figure 3. Traditional design vs. Design Thinking. 
We used the following Design Thinking tools to delve into the feelings and motivations of the user and understand why they do not use the Patsari model installed in their home. To gain empathy we have used the 'Persona' tool for drawing an archetype of the final user of the cook stove (Figure 4). This tool focuses the work of the designer to a specific customer. In our case, we have focused our effort in Ms. Chela (a simulated name). The 'Persona' is a fictitious but realistic user. She is a middle-age woman, living at Sta. Ana Chapitiro and accomplishes all the necessary characteristics to be applied to the redesign of the cook stove. We have conducted interviews with the three women who had installed the prototype in their homes as the main users of the new Patsari cook stove. To do so we had one person in the field watching, taking notes and speaking with these women, making observations about how they picked up firewood, how they cooked and how these women felt.

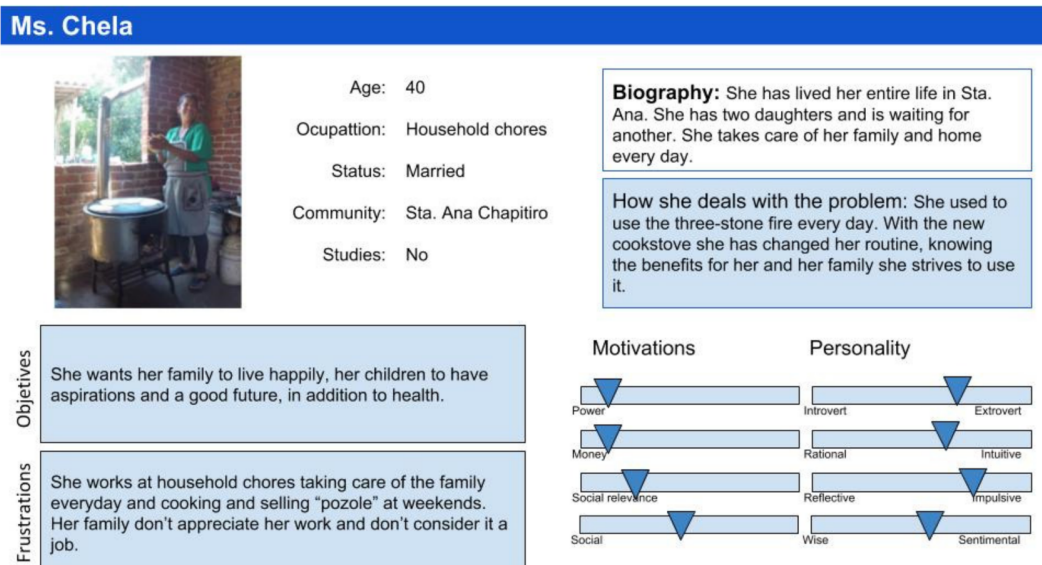

Figure 4. 'Persona' Tool.

We also used an Empathy Map (Figure 5) to understand their feelings, thoughts and beliefs, and the Journey Map tool to show the satisfaction of different actions and procedures that these women could do in their daily use of the cook stove prototype (Figure 6). As we can see, the user found some operations as unsatisfactory, which is very useful to the designer focusing on those facts to develop solutions that help to solve these problems. We put our focus on obtaining a homogenous heat, which is a crucial point to cook traditional 'tortillas'.

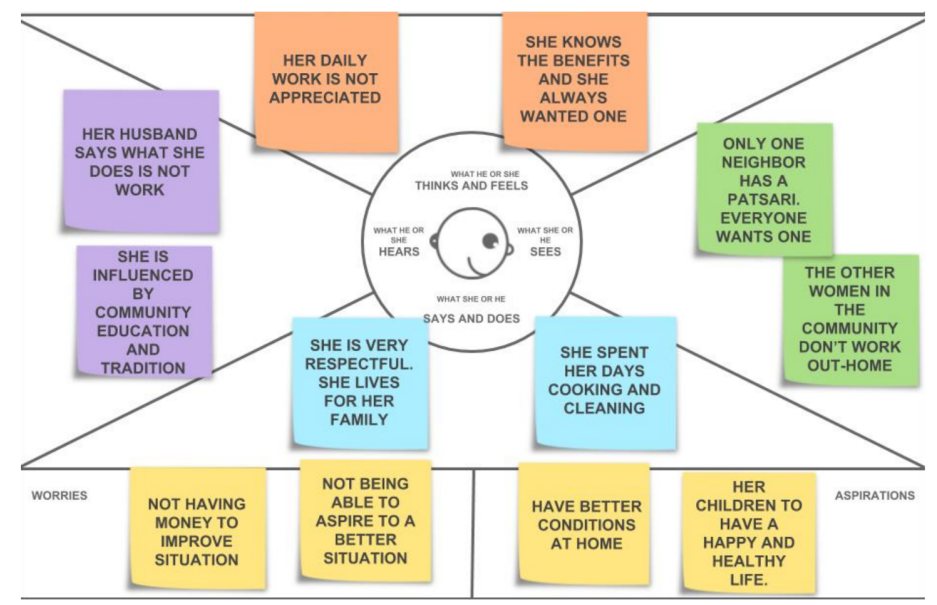

Figure 5. Empathy Map developed.

Also, a cause-effect diagram or Ishikawa diagram has been drawn to detect the main needs of the cook stove, making it possible to improve the design and reduce the combustion emissions (Figure 7) for prototype 1. 
The Water Boiling Test (WBT) and the temperature distribution test were used for a correct evaluation of the cook stove performances according to warming and efficiency, which shows the energy efficiency in terms of heat transfer and combustion efficiency. The temperature was measured by using a contact Fluke 50 Serie II Thermometer and a Fluke TI400 thermographic camera. The obtained data was used to calculate its performance in respect with different technical criteria set up (temperature reached in the comal and its symmetry, heat distribution in rings, temperature reached in the chimney, thermal efficiency and heat loss between rings).

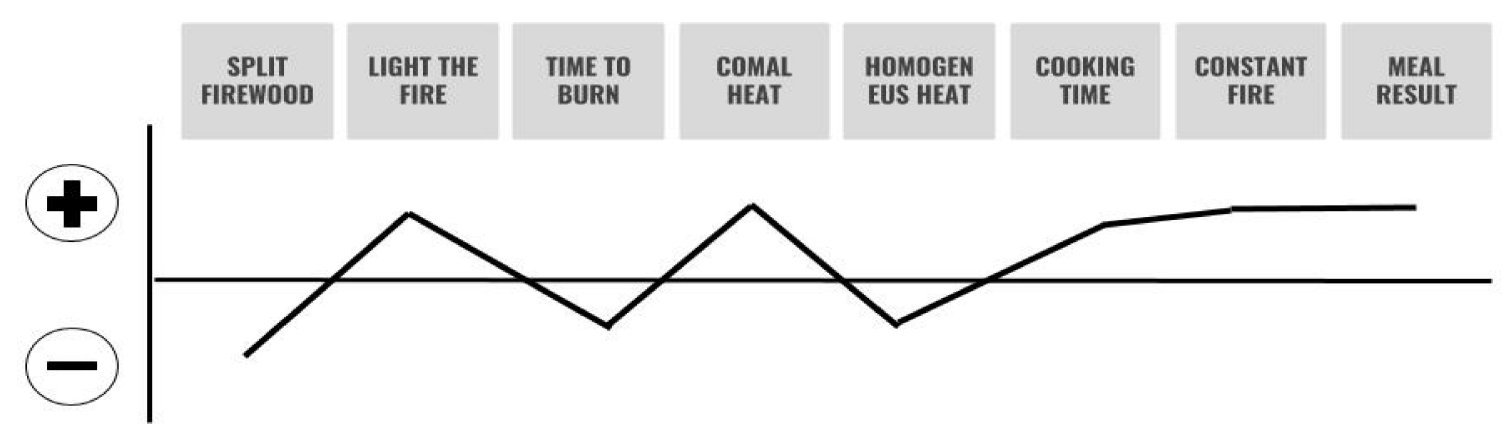

Actions

She cannot collect firewood because of the pregnancy so she burns any type of firewood she finds Smoke is coming out from the inlet..

She puts the "tortillas" near to the comal edge because the center and the inferior part are too hot.

Feelings

It takes more time to burn.

It takes the same time to cook but the fire is more constant and she can do more than one task at the same time..

It heats very well.

The housing is heating too much and she doesn't like smoke coming out.

Figure 6. Journey Map of the three-chamfer prototype user evaluation.

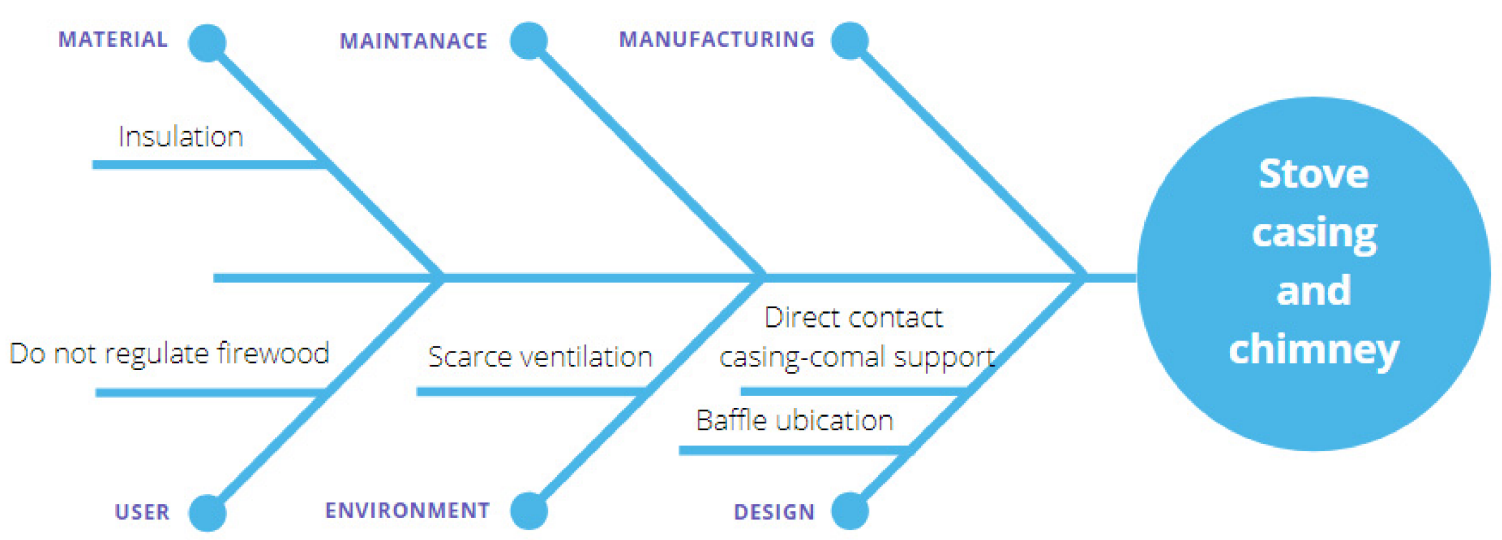

Figure 7. Ishikawa diagram of prototype 1.

Finally, a FEM model was developed using SolidWorks $@$ (assembling design) and ANSYS @ (inner volume) software to analyze the theoretical behavior of the prototypes, doing the corresponding simulation with Fluent platform. A forced convection model was studied according to which hot air $(700 \mathrm{~K})$ gets in the combustion inlet, the air volume transferred to the comal and chimney by convection and conduction, finally leaving to the atmosphere through the chimney. In addition, the model was adjusted to the theoretical 
behavior of the cook stove for a correct calculation of comal and chimney temperature, Nusselt number, drift coefficient and thermal efficiency [23,24].

\section{Results}

After the analysis in situ, we observed that the original portable Patsari model failed because the full structure warmed up too much and it was impossible to use, probably as consequence of the elbow that exists to communicate the combustion chamber with the comal support.

To improve the behavior of the portable Patsari, prototype 1 had a modification between the combustion chamber and the platform that sustains the comal, connecting them with a four edges nozzle to increase the air transit area, and a baffle to hamper the hot air and improve the air quality into the room. In addition, it had a partial circular shape for better manipulation. This prototype was installed in a kitchen of a family at Sta. Ana de Chapitiro.

The technical test, modeling, simulation and user evaluation were performed and all the information obtained was evaluated with the GIRA technicians using Design Thinking tools and the Ishikawa diagram, defining the potential causes of the problem (Figure 8). The main problem was analyzed, concluding that the stove casing and the chimney were warming up too much due to the fast exhaust of the air through the chimney, which also implied an efficiency reduction.
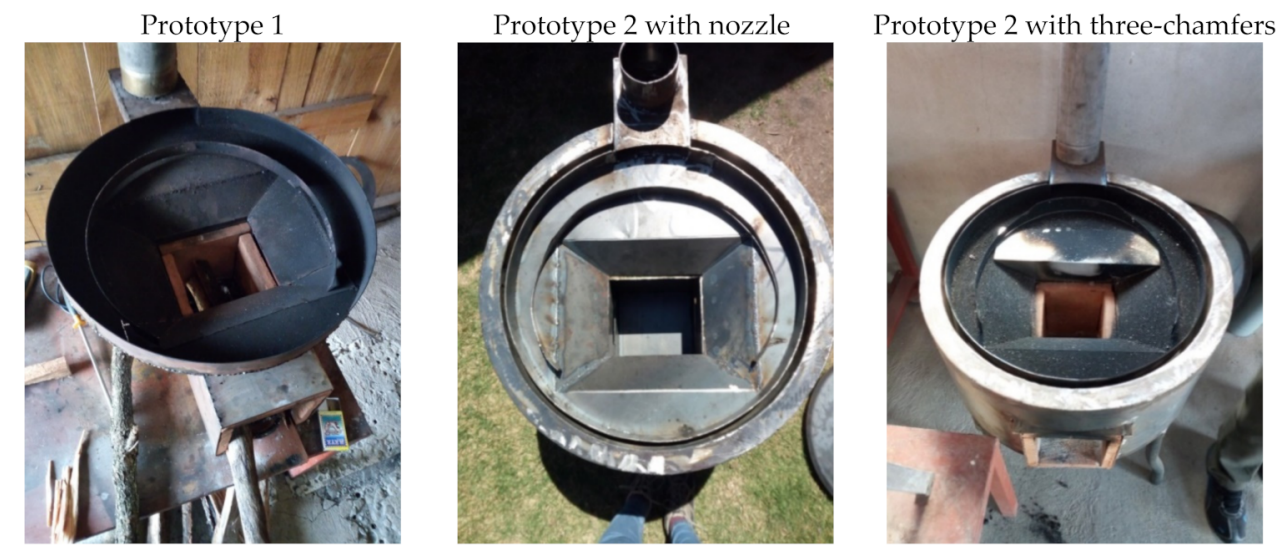

Figure 8. The Patsari prototypes.

After selecting the areas and causes that could be changed and using tools to generate ideas in-group like brainstorming, the potential solutions were studied and two prototypes were developed as a progress. Firstly, a hole was added between the stove casing and the comal platform to improve the air recirculation around the combustion chamber. Secondly, the baffle geometry was redesigned to increase the height of the nearest part to the chimney and decrease air losses (one of the prototypes had only three edges communicating the combustion chamber and the comal platform after elimination of the nearest chamfer to the chimney, Figure 8). After these changes it was possible to study both prototypes, one with the four-edge nozzle and the other one with three chamfers, to evaluate the performance of each and discard one of them.

\section{Discussion}

After a first approach to theoretical calculation of the experimental ones was achieved, the results of the simulations and the technical criteria showed that the three chamfers prototype had better heat transfer in the comal, resulting in higher temperatures (Table 1). 
Table 1. Technical criteria results.

\begin{tabular}{ccccccc}
\hline & $\begin{array}{c}\text { Tav Chimney } \\
\left({ }^{\circ} \mathbf{C}\right)\end{array}$ & $\begin{array}{c}\text { Tav Comal } \\
\left({ }^{\circ} \mathbf{C}\right)\end{array}$ & $\begin{array}{c}\text { St. Dev Tav } \\
\left({ }^{\circ} \mathbf{C}\right)\end{array}$ & Symmetry & WBT & $\begin{array}{c}\text { Thermal } \\
\text { Efficiency } \boldsymbol{E}\end{array}$ \\
\hline Prototype 1 & 152.38 & 197.67 & 61.32 & $16.32 \%$ & $42 \%$ & $82.60 \%$ \\
Prototype 2 with nozzle & 110.38 & 298.68 & 36.2 & $10.36 \%$ & $51 \%$ & $80.67 \%$ \\
Prototype 2 with three chamfers & 140.5 & 334.58 & 29.87 & $5.37 \%$ & $57 \%$ & $81.45 \%$ \\
\hline
\end{tabular}

The experimental test was based on the measurement nine standard points distributed on the comal (one located in the center, four sited in a diameter of $30 \mathrm{~cm}$ and four more points in a diameter of $40 \mathrm{~cm}$ ) and made every $5 \mathrm{~min}$ for the $40 \mathrm{~min}$ of the test. It was carried out under similar conditions of firewood between the different prototypes of the cook stoves in order to observe in turn the expense of firewood without any other load on the comal.

The standard points where the temperature was measured are shown in Figure 9a and the following calculations were made by considering the data collected and technical criteria for evaluating the stove:

- $\quad$ Average temperature in the comal (Tav) considering the values of the different measurements saved during the test.

- Symmetry considering the temporal average of each point. By considering the measured values, the difference was calculated considering its symmetrical point in the comal, obtaining in this way a temperature difference between symmetrical points. To obtain a normalized value, this difference was divided between the Tav of the comal; being more symmetrical, the temperature distribution when smaller is the temperature difference from the different points.

- Distribution rings: the mean of the points measured in each ring (Points 1 to 9 of Figure 9a) was performed. To do it, the average temperature values in each time interval during the $40 \mathrm{~min}$ were determine; after the mean of these values in each corresponding ring was obtained. The result obtained was a graph with the temporal evolution of the temperature reached by each one, being essential for the user to find a hotter spot in the center and cooler edges for the cooking of tortillas and also have a warmer focus for boiling tasks.

- Thermal efficiency E: corresponding with the relationship between the energy produced and the energy supplied by performing the theoretical calculation through the heat exchange cycle. Heat $(Q)$ is defined as:

$$
Q=C \Delta T
$$

where $C$ is the heat capacity of the fluid subject to temperature change and $\Delta T$ is the difference in temperature, being proportional to the energy absorbed in the system. Therefore, the thermal efficiency $E$ being the ratio between the energy produced between the supplied energy would be:

$$
E=\frac{\text { Qreal }}{Q \max }=\frac{C(\text { Tskillet }- \text { Tamb })}{C(\text { Tin }- \text { Tamb })}=\frac{\text { Tskillet }- \text { Tamb }}{\text { Tin }- \text { Tamb }}
$$

where Tin is the input temperature, equivalent to the average temperature at the outlet point of the combustion chamber, Tamb is the ambient temperature and Tcomal is the average temperature that exists on the surface of the comal.

The results of these technical criteria are collected in Table 1 and Figure 9. Prototype 2 with three chamfers had better performance. It reached a higher average temperature, and had better heat distribution and better thermal efficiency.

In addition, different simulations were performed with the ANSYS program to study and analyze the thermal efficiency after applying the different modifications of the geometries. Before modelling the phenomena, it was necessary to discretize the spatial model of the inner volume by using a mesh composed by hexahedral elements, as shown in Figure 10 after different modelling and refinement stages. 
We studied the phenomenon of forced convection introducing hot air flow through the entrance of the combustion chamber, where the firewood was introduced. This flow was distributed by volume, transmitting part of its temperature to the comal and the chimney by using natural convection and driving to finally exit through the chimney. The reported thermal power was in the range of 5 to $10 \mathrm{~kW}$, resembling the experimental WBT and using powers, based on the input speed.

$$
d Q=\rho \cdot v \cdot A \cdot C p \cdot d T
$$

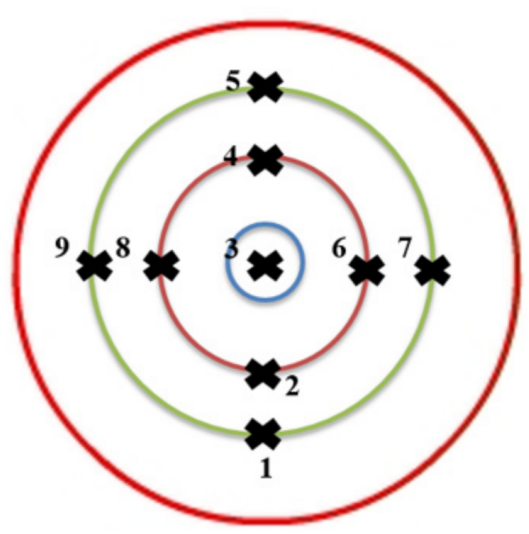

(a)

\section{Prototype 1}

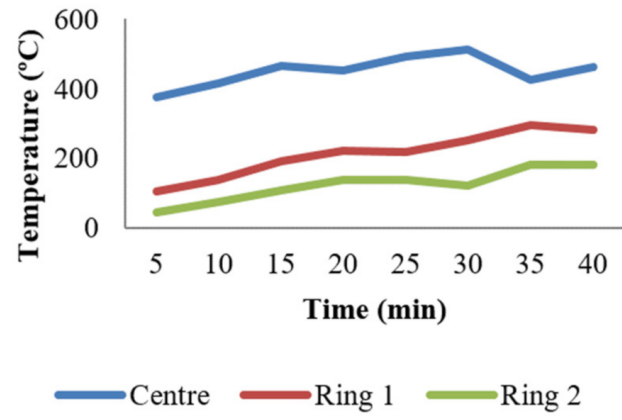

Prototype 2 with Nozzle

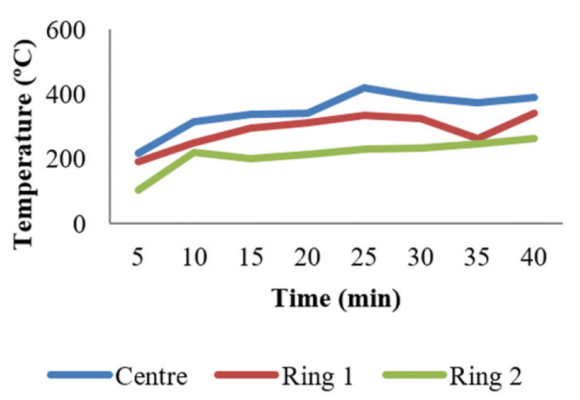

Prototype 2 with three chamfers

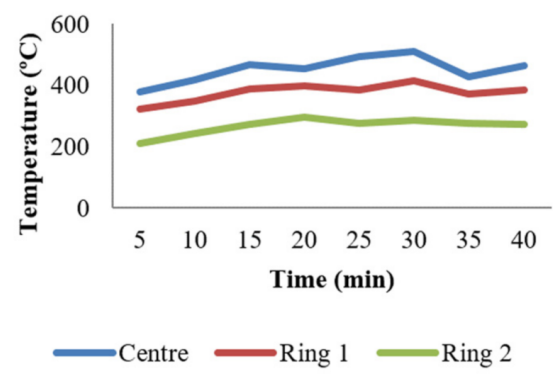

(b)

Figure 9. (a) The standard points where the temperature was measured in diameters of 20, 30, 40 and $50 \mathrm{~cm}$. (b) Temperature evolution by rings in the comal for the prototypes. 

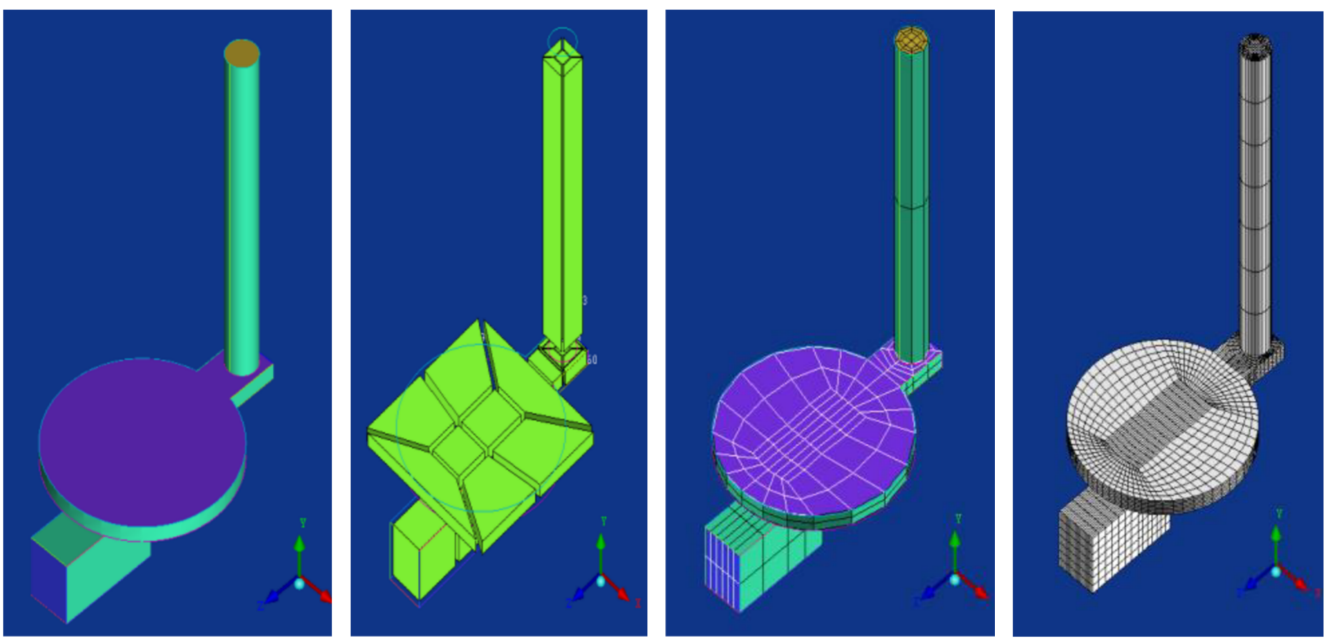

Figure 10. Meshing process from the inner volume in ANSYS of prototype 2.

Depending on the temperature density $\rho$ and making the relevant approximations, the power ratio to the temperature and input speed is as follows:

$$
Q=V \cdot A \cdot \Delta T \cdot \frac{P \cdot m}{R \cdot T}
$$

where $v$ is the inlet speed, $A$ the inlet area which is equal to $23,061.76 \mathrm{~mm}^{2}, T$ the temperature difference between the inlet and the ambient outlet, $P$ the ambient pressure, $m$ the molecular mass of the air equal to $28.84 \mathrm{~g} / \mathrm{mol}, R$ the ideal constant of the gases and $T$ the temperature at the inlet.

One of the most significant conclusions after analyzing the simulations results is the relevance of the baffle, which increases the comal temperature and reduces the chimney temperature, improving efficiency. It is reaffirmed with the fact that the original model showed the worst results, warming up too much so it was not possible to cook, that there was no symmetry and the efficiency was the lowest. The ANSYS results showed a higher temperature in the nozzle prototype 2 but a better heat transfer of the three chamfers redesign, represented by Nusselt number (Figure 11).

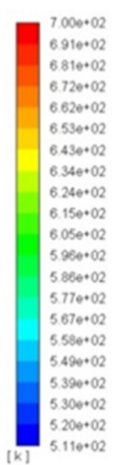

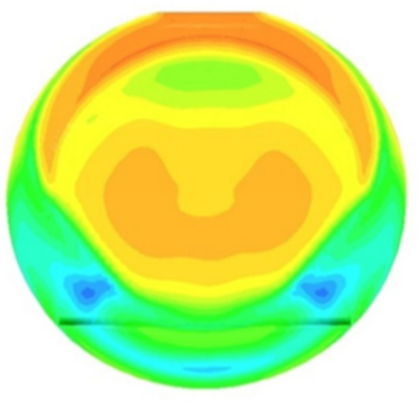

(a)

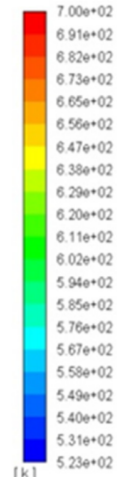

(b)

Figure 11. ANSYS@ comal temperature results for (a) prototype 2 with nozzle (b) prototype 2 with three chamfers.

It is important to emphasize that the differences of the results of both prototypes 2 models were small in both experimental and theoretical tests, being the difference in the comal temperature, as the thermal or cooking efficiency, few points in all the cases. 
Nevertheless, when the prototypes were evaluated by the user (Figure 12), the three chamfers model was not totally adapted to the user cooking techniques and needs. For example, one of the users was pregnant; she could not walk far and select good quality wood, so the cook stove returned the entire smoke from the inlet because she was using humid pine firewood which produces too much soot. On the other hand, when the nozzle model was tested it showed a proper heat comal transfer with high temperatures and there was not smoke returning, so she was satisfied.

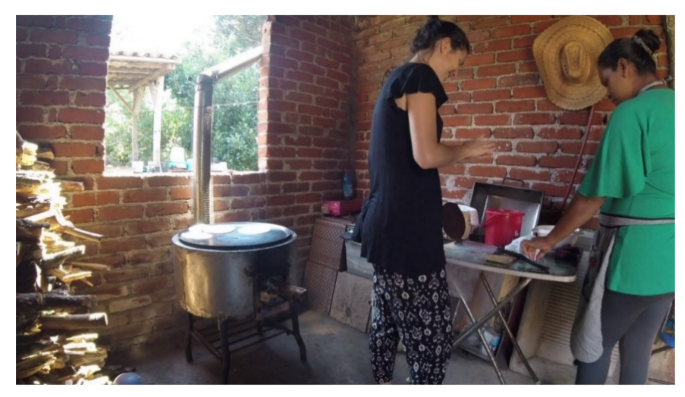

Figure 12. Testing the portable-metallic Patsari by users.

\section{Conclusions}

Traditionally, improved cook stoves development projects have been divided in two ways. On the one hand, the correct performance of the stoves is analyzed by measuring efficiency and emissions under laboratory conditions. On the other hand, the study of adoption and monitoring of the stoves is carried out once installed.

This work allows a better understanding of the Patsari cook stove and the needs that must be covered after jointly studying the different perspectives, ensuring in a better way higher adoption rates and the project success. We have observed that even if a prototype offers good technical results, sometimes it does not achieve the expected acceptance due to cultural traditions or user usage. For this reason, it is very important to include these topics in the kitchen using Design Thinking or any other co-creation methodology that incorporates the different points of view of the users. The use of tools based on Design Thinking methodology to design and develop improved cook stoves that were used in this project has shown the importance and relevance that takes the assessment of the users.

The technical criteria defined in this study to analyze the experimental performance allowed us to discuss the information clearly and it would be useful to define some user metrics to more easily assess the design process in future projects. Additionally, its use would avoid the failure that commonly occurs in these type of projects.

The economic and social situation of the population where the cook stoves are implemented can be hugely different, so it is especially important to consider them at the first stages of design projects according to the observed needs of the users and the technical observations during the development of the work. Other design criteria for future Patsari cook stoves could be the flexibility in the use of different qualities of firewood, the heating of the comal, the smoke outlet, the ability to cook multiple types of dishes, the safety of the stove and the heating of the chimney.

Author Contributions: Formal analysis, B.S. and A.B.; Investigation, E.F.B. and O.M.; Methodology, L.M.M., A.B. and V.B.; Supervision, L.M.M. and O.M.; Validation, G.R.R., A.B. and V.B.; Writingoriginal draft, E.F.B.; Writing —review and editing L.M.M. and B.S. All authors have read and agreed to the published version of the manuscript.

Funding: This research was supported by the project SENER CONACYT 2014246911 "Clúster de biocombustibles sólidos para generación térmica y eléctrica".

Institutional Review Board Statement: Not applicable.

Informed Consent Statement: Not applicable. 


\section{Data Availability Statement: Not applicable.}

Acknowledgments: We want to thank the support to all persons of Instituto de Investigación en Materiales (IIM) of the Universidad Autónoma de México (UNAM), located at Morelia, and the Grupo Interdisciplinario de Tecnología Rural Apropiada (GIRA), sitted Pátzcuaro.

Conflicts of Interest: The authors declare no conflict of interest.

\section{References}

1. Bailis, R.; Drigo, R.; Ghilardi, A.; Masera, O. The carbon footprint of traditional woodfuels. Nat. Clim. Chang. 2015, 5, 266-272. [CrossRef]

2. FAOSTAT Forestry Production and Trade. Available online: http://faostat3.fao.org/faostat-gateway/go/to/download/F/*/E (accessed on 5 September 2020).

3. Masera, O.R.; Bailis, R.; Drigo, R.; Ghilardi, A.; Ruiz-Mercado, I. Environmental burden of traditional bioenergy use. Annu. Rev. Environ. Resour. 2015, 40, 121-150. [CrossRef]

4. World Health Organization. Household Air Pollution and Health. 2018. Available online: http://www.who.int/es/news-room/ fact-sheets/detail/household-air-pollution-and-health (accessed on 5 September 2020).

5. Romieu, I.; Riojas-Rodriguez, H.; Marrón-Mares, A.T.; Schilmann, A.; Perez-Padilla, R.; Masera, O. Improved biomass stove intervention in rural Mexico: Impact on the respiratory health of women. Am. J. Respir. Crit. Care Med. 2009, 180, 649-656. [CrossRef] [PubMed]

6. Anenberg, S.C.; Balakrishnan, K.; Jetter, J.; Masera, O.; Mehta, S.; Moss, J.; Ramanathan, V. Cleaner cooking solutions to achieve health, climate, and economic cobenefits. Environ. Sci. Technol. 2013, 47, 3944-3952. [CrossRef] [PubMed]

7. Schilmann, A.; Riojas-Rodríguez, H.; Catalán-Vázquez, M.; Estevez-García, J.A.; Masera, O.; Berrueta-Soriano, V.; Romieu, I. A follow-up study after an improved cook stove intervention in rural Mexico: Estimation of household energy use and chronic PM2. 5 exposure. Environ. Int. 2019, 131, 105013. [CrossRef] [PubMed]

8. Peralta, O.; Ortínez-Alvarez, A.; Basaldud, R.; Santiago, N.; Alvarez-Ospina, H.; de la Cruz, K.; Martínez-Arroyo, A. Atmospheric black carbon concentrations in Mexico. Atmos. Res. 2019, 230, 104626. [CrossRef]

9. Gobierno de México. Usuarios de Leña en México. Available online: https://www.gob.mx/cofepris/acciones-y-programas/3usuarios-de-lena-en-mexico (accessed on 5 September 2020).

10. Food and Agriculture Organization of the United Nations. The Potential Use of Wood Residues for Energy Generation. Available online: http:/ / www.fao.org/3/t0269e/t0269e08.htm (accessed on 5 September 2020).

11. Rehman, I.H.; Ahmed, T.; Praveen, P.S.; Kar, A.; Ramanathan, V. Black carbon emissions from biomass and fossil fuels in rural India. Atmos. Chem. Phys. Discuss. 2011, 11, 10845-10874.

12. Johnson, M.A.; Edwards, R.; Ghilardi, A.; Berrueta, V.; Masera, O. Why current assessment methods may lead to significant underestimation of GHG reductions of improved stoves. Boil. Point 2007, 54, 11-14.

13. Rodolfo, D.J.; Victor, B.; Omar, M. Estufas de Leña. Red Mexicana de Bioenergía, A.C. 2011. Available online: http://rembio.org. $\mathrm{mx} /$ wpcontent/uploads/2014/12/CT3.pdf (accessed on 5 September 2020).

14. Urmee, T.; Gyamfi, S. A review of improved Cookstove technologies and programs. Renew. Sustain. Energy Rev. 2014, 33, 625-635. [CrossRef]

15. Masera, O.R.; Díaz, R.; Berrueta, V. From cook stoves to cooking systems: The integrated program on sustainable household energy use in Mexico. Energy Sustain. Dev. 2009, 9, 25-36. [CrossRef]

16. Tauro, R.; Serrano-Medrano, M.; Masera, O. Correction to: Solid biofuels in Mexico: A sustainable alternative to satisfy the increasing demand for heat and power. Clean Technol. Environ. Policy 2018, 20, 1541. [CrossRef]

17. Ruiz-Mercado, I.; Masera, O.; Zamora, H.; Smith, K.R. Adoption and sustained use of improved cook stoves. Energy Policy 2011, 39, 7557-7566. [CrossRef]

18. Van der Kroon, B.; Brouwer, R.; Van Beukering, P.J. The energy ladder: Theoretical myth or empirical truth? Results from a meta-analysis. Renew. Sustain. Energy Rev. 2013, 20, 504-513. [CrossRef]

19. Medina, P.; Berrueta, V.; Cinco, L.; Ruiz-García, V.; Edwards, R.; Olaya, B.; Schilmann, A.; Masera, O. Understanding Household Energy Transitions: From Evaluating Single Cookstoves to "Clean Stacking". Altern. Atmos. 2019, 10, 693. [CrossRef]

20. Brown, T.; Katz, B. Change by Design: How Design Thinking Transforms Organizations and Inspires Innovation; HarperBusiness: New York, NY, USA, 2019; Volume 20091.

21. Liedtka, J. Designing for Growth: A Design Thinking Tool Kit for Managers; Columbia University Press: New York, NY, USA, 2011; ISBN 978-0231158381.

22. Brown, T. Change by Design; Hasper Collins: New York, NY, USA, 2019; ISBN 0062856626.

23. Núñez, J.; Moctezuma-Sánchez, M.F.; Fisher, E.M.; Berrueta, V.M.; Masera, O.R.; Beltrán, A. Natural-draft flow and heat transfer in a plancha-type biomass cookstove. Renew. Energy 2020, 146, 727-736. [CrossRef].

24. Medina, P.; Núñez, J.; Ruiz-García, V.M.; Beltrán, A. An Experimental and numerical comparison of $\mathrm{CO}_{2}$ mass flow rate emissions, combustion and thermal performance for a biomass plancha-type cookstove. Energy Sustain. Dev. 2021, 63, 153-159. [CrossRef]. 